\title{
ESTAQUIA DE OLIVEIRA EM DIFERENTES ÉPOCAS, SUBSTRATOS E DOSES DE AIB DILUÍDO EM NAOH E ÁLCOOL ${ }^{1}$
}

\author{
Rooted stem cutting of the olive tree in different times, substrates and doses of IBA \\ dilluted in $\mathrm{NaOH}$ and alcohol
}

\author{
Adelson Francisco de Oliveira², Nilton Nagib Jorge Chalfun ${ }^{3}$, Ângelo Albérico Alvarenga², \\ João Vieira Neto ${ }^{4}$, Rafael Pio ${ }^{5}$, Dili Luiza de Oliveira $^{6}$
}

\begin{abstract}
RESUMO
A estaquia é um método de propagação muito utilizado para a oliveira. Sua viabilidade depende da capacidade de formação de raízes adventícias de cada espécie. Contudo é necessário estudar as diferentes características desse processo. Objetivou-se, no presente trabalho avaliar o efeito de concentrações de AIB, do veículo de diluição, do substrato e época de coleta, no enraizamento de estacas semilenhosas de oliveira 'Ascolano 315'. Foram coletados ramos medianos de plantas matrizes localizadas na unidade da Epamig, em Maria da Fé-MG, e preparadas as estacas com, aproximadamente, $12 \mathrm{~cm}$ de comprimento, com 4 a 6 internódios, mantendo na região apical quatro folhas. O delineamento utilizado foi o inteiramente casualizado, em esquema fatorial 4 × 2 × 2 × 5 , com quatro repetições e quinze estacas por parcela. $\mathrm{O}$ experimento foi conduzido em câmara úmida, com fornecimento de calor no fundo das bandejas de enraizamento. Após a instalação do experimento, foi realizado um tratamento com solução de oxicloreto de cobre a $3 \%$, para prevenir eventuais ataques de fungos e, a cada sete dias, a câmara foi aberta por alguns minutos para renovação do ar e irrigação, para manutenção da umidade. As avaliações foram realizadas 65 dias após a estaquia de cada época de coleta. As estacas coletadas em abril e tratadas com $3000 \mathrm{mg} . \mathrm{L}^{-1}$ apresentaram maior porcentagem de enraizamento e número médio de raízes. O substrato perlita + vermiculita $(1: 1 \mathrm{v} / \mathrm{v})$ incrementou o comprimento médio das raízes. A diluição do AIB em NaHO ou álcool + água não diferiu.
\end{abstract}

Termos para indexação: Olea europaea L., propagação, enraizamento, meios diluição.

\section{ABSTRACT}

The rooted stem cutting is a method highly used for the propagation of olive tree. Its viability depends on the capacity of each species to form adventitious roots. However, it is necessary to study the different characteristics of this process. The objective of the present work was to evaluate the effect of IBA concentrations, the dilution carrier, the substrate and the times of collection on the rooting of the semi-hardwood stem cuttings of olive tree "Ascolano 315'. Median branches of stock plants located at the EPAMIG unit in Maria da Fé-MG have been collected and cuttings about 12 centimeters in length with 4 to 6 units of internodes were prepared, with four leaves being kept in the apical region. The experimental design was the completely randomized in a factorial scheme $4 \times 2$ $\mathrm{x} 2$ x 5, with four replications and fifteen cuttings per plot. The experiment was carried out in a moist chamber with the supply of heat at the bottom of the rooting trays. After the experiment was established, a treatment was accomplished with a solution of 3\% copper oxychloride to prevent occasional fungal attacks and every seven days, the chamber was opened for a few minutes for air renewal and irrigation for maintenance of moisture. The evaluations were accomplished 65 days after the staking of cuttings from each collection time. The cuttings collected in April and treated with 3,000 mg.L $\mathrm{L}^{-1} \mathrm{IBA}$ showed increased percentage of rooting and average number of roots. The perlite + vermiculite $(1: 1 \mathrm{v} / \mathrm{v})$ enhanced the average length of the roots. The dilution of IBA in $\mathrm{NaOH}$ or alcohol + water did not present difference.

Index terms: Olea europaea L., propagation, rooting, dilution media.

(Recebido em 22 de fevereiro de 2007 e aprovado em 20 de julho de 2007)

\section{INTRODUÇÃO}

A oliveira (Olea europaea L.) pertence à família Oleaceae, que inclui cerca de 30 gêneros, como o Fraxinus,
Ligustrum, Syringa e Olea (OLIVEIRA \& ABRAHÃO, 2006). O cultivo de oliveiras adquiriu especial relevância em todo mundo em razão do azeite de oliva ser comprovadamente benéfico à saúde humana, na proteção

\footnotetext{
${ }^{1}$ Apoio FAPEMIG

Engenheiros Agrônomos, Doutores, Pesquisadores - Empresa de Pesquisa Agropecuária de Minas Gerais/EPAMIG - Centro Tecnológico Sul de Minas Gerais/CTSM - Cx. P. 176 - 37200-000 - Lavras, MG - adelson@epamig.ufla.br; angelo@epamig.ufla.br - Bolsista Fapemig

${ }^{3}$ Doutor, Professor - Departamento de Agricultura/DAG - Universidade Federal de Lavras/UFLA - Cx. P. 3037 - 37200-000 - Lavras, MG nchalfun@ufla.br

${ }^{4}$ Engenheiro Agrônomo, Doutor, Pesquisador - Empresa de Pesquisa Agropecuária de Minas Gerais/EPAMIG - Fazenda Experimental de Maria da Fé/ FEMF - Fazenda Experimental de Maria da Fé - Vargedo - 35517-000 - Maria da Fé, MG - joaovieira@epamig.ufla.br - Bolsista Fapemig

${ }^{5}$ Engenheiro Agrônomo, Doutor, Professor Adjunto - Departamento de Agricultura/DAG - Universidade Estadual do Oeste do Paraná/UNIOESTE - Rua Universitária, 1619 - Jardim Universitário - Cx. P. 701 - 85819-110 - Cascavel, PR - rafaelpio@hotmail.com

${ }^{6}$ Bióloga, Doutoranda - Departamento de Agricultura/DAG - Universidade Federal de Lavras/UFLA - Cx. P. 3037 - $37200-000$ - Lavras, MG dililuiza@gmail.com
} 
de enfermidades cardiovasculares, e por ser muito utilizado como veículo na confecção de produtos farmacêuticos (MESQUITA et al., 2006).

O Brasil é um dos maiores importadores de produtos de oliveira da América do Sul, sendo a Argentina um dos mais importantes fornecedores, além da Espanha e de Portugal (CASTRO et al., 1997). O cultivo de oliveiras no Brasil é recente, com novos plantios comerciais iniciados na região Sul do Estado de Minas Gerais. Essa commodity, além de diminuir os gastos com importações, possibilitará maior arrecadação de impostos diretos (MESQUITA et al., 2006).

Apesar dos frutos da oliveira possuírem sementes viáveis, a reprodução sexual não é desejada no estabelecimento de plantios comerciais, porque as plantas assim obtidas serão distintas da planta- mãe e apresentarão longo período juvenil.

Sendo assim, a propagação vegetativa por estaquia ou através da enxertia vem a ser a técnica mais viável para o processo de formação de mudas, mantendo as características genéticas das plantas matrizes, uniformidade, porte reduzido e precocidade de produção (FACHINELLO et al., 2005a; HARTMANN et al., 2002).

A estaquia é um método de propagação muito utilizado, sendo sua viabilidade dependente da capacidade de formação de raízes adventícias de cada espécie, da qualidade do sistema radicular formado e do desenvolvimento posterior da planta na área de produção (FACHINELLO et al., 1995b). Este método explora a possibilidade das plantas regenerarem raízes a partir de um segmento de ramo, ou de um segmento de raízes (FACHINELLO et al., 2005a; HARTMANN et al., 2002).

A oliveira sempre foi propagada por estaquia. Inicialmente foram utilizadas estacas de grande tamanho (50-60 cm de comprimento e até $5 \mathrm{~cm}$ de diâmetro), enterradas diretamente na área de plantio definitivo, e posteriormente, com estacas menores (25-30 cm de comprimento e diâmetro também de até $5 \mathrm{~cm}$ ), em sacolas de plástico, em viveiro. Entretanto, em ambos os casos, são observadas desvantagens, como a necessidade de grande quantidade de material vegetativo e maior tempo para a formação da muda. $\mathrm{Na}$ estaquia a processo exige, pelo menos, dezoito meses de cuidados especiais, que poderiam ser realizados no viveiro, onerando sobremaneira o custo inicial da cultura (CABALLERO, 1981; OLIVEIRA, 1998).

O enraizamento de estacas utilizando estrutura de nebulização intermitente e com mecanismos que permitem o aquecimento do substrato, em ambientes protegidos ou telados, possibilitou notáveis avanços na propagação de inúmeras espécies vegetais, inclusive da oliveira.
Entretanto, são necessários investimentos iniciais altos, com a construção de instalações apropriadas, o que pode dificultar a adoção desta tecnologia por muitos viveiristas ou pequenos agricultores.

Segundo alguns pesquisadores (JACOBONI et al., 1976; PORRAS et al., 1998), a adoção de "camas quentes", ou seja, de leitos de enraizamento protegidos com plástico transparente e a utilização de algum sistema de aquecimento do substrato, diminuem substancialmente o custo inicial das instalações, com porcentuais de enraizamento, para algumas espécies e variedades, muito próximos aos obtidos em câmara de nebulização intermitente.

Para manter a temperatura do substrato entre 20 e $24{ }^{\circ} \mathrm{C}$, pela passagem de ar quente, utilizando aquecedores, Piedra et al. (1992), adaptaram uma tecnologia de controle elétrico automático, possibilitando a homogeneidade da temperatura da massa de substrato, obtendo sucesso no enraizamento de diferentes espécies de plantas, sob nebulização intermitente e em túnel plástico. Os porcentuais de enraizamento de estacas variaram de 50 a $80 \%$, inclusive da oliveira.

Assim, no presente trabalho, avaliou-se o efeito da época de coleta das estacas, de concentrações de AIB, do veículo diluição do AIB e de substratos no enraizamento de estacas semilenhosas de oliveira, acondicionadas em câmara úmida, com fornecimento de calor no fundo das bandejas de enraizamento.

\section{MATERIAL E MÉTODOS}

A pesquisa foi conduzida na Fazenda da Epamig, localizada no município de Maria da Fé, microregião da serra da Mantiqueira, Sul de Minas Gerais.

Para instalação do experimento, foram utilizadas plantas da cultivar Ascolano 315, da coleção mantida na unidade da Epamig, em Maria da Fé, sendo colhidas estacas semilenhosas na região mediana em torno da copa.

$\mathrm{O}$ delineamento experimental utilizado foi o inteiramente casualizado, com os tratamentos arranjados no esquema fatorial $5 \times 2 \times 2 \times 4$, com quatro repetições e 15 estacas por parcela, compreendendo cinco épocas de coleta das estacas (abril, maio, junho, julho e agosto); dois substratos (perlita agrícola e perlita agrícola mais vermiculita 1:1 - v/v); dois veículos de diluição do AIB (em solução de hidróxido de sódio, diluindo o AIB em solução 0,5 normal $\mathrm{NaOH}$, completando o volume com água de acordo com a concentração, e solução hidroalcóolica 1:1 v/v diluindo o AIB em álcool $98 \%$, completando-se o volume com água de acordo com a concentração); e quatro concentrações do regulador AIB 0, 1000, 2000 e 3000 mg.L $\mathrm{L}^{-1}$. 
As estacas foram preparadas com aproximadamente $12 \mathrm{~cm}$ de comprimento e 4 a 6 internódios, mantendo na região apical as mesmas quatro folhas. $\mathrm{O}$ tratamento com o AIB foi realizado por imersão de $3 \mathrm{~cm}$ da base das estacas, por cinco segundos na solução contendo o produto.

$\mathrm{O}$ experimento foi conduzido em câmara úmida $(2 \mathrm{~m}$ de comprimento por $1 \mathrm{~m}$ de largura e altura de 1,20 m), disposta sob uma estrutura protegida com sombrite $50 \%$ e, sobre ele, plástico transparente para proteger de chuvas. $\mathrm{O}$ fundo da câmara e as laterais, na metade inferior, foram vedadas com madeirite $10 \mathrm{~mm}$ e, na metade superior, com chapa de policarbonato multilux alveolar. Na parte interna da câmara úmida foram acondicionadas duas bandejas, dispostas lado a lado, confeccionadas em chapa galvanizada de $0,65 \mathrm{~mm}$, nas dimensões de $1 \mathrm{~m}$ por $0,88 \mathrm{~m}$ e profundidade de $0,20 \mathrm{~m}$, com um pequeno tubo em uma das laterais, para drenagem do excesso de água.

Com o objetivo de aquecer o substrato por difusão de calor, foram instaladas internamente na estrutura da câmara e sob as bandejas de chapa galvanizada, três lâmpadas infravermelhas (250 Watts - 127 Volts) em série, ligadas à corrente elétrica por um temporizador 24 horas (127/220 Volts, frequiência $60 \mathrm{~Hz}$, potência de $1270 \mathrm{Watts})$, regulado para ligar o sistema por 15 minutos a cada uma hora, das 18 horas da tarde às 8 horas da manhã do dia seguinte.

Para a instalação do experimento, o substrato de enraizamento foi irrigado antes do plantio das estacas, sendo também realizado um tratamento com solução de oxicloreto de cobre a $3 \%$, com o objetivo de prevenir eventuais ataques de fungos, repetido cada época de instalação. A cada sete dias a câmara foi aberta por alguns minutos para renovação do ar e realizada nova irrigação.

A estaquia teve início em 19 de abril de 2005, sendo repetida a cada mês testado. As avaliações foram realizadas 65 dias após o plantio das estacas. Para a indicação de sobrevivência das estacas foram anotadas as seguintes características: porcentagem de estacas com calos e enraizadas, número e comprimento médio de raízes.

Os dados coletados foram analisados estatisticamente, utilizando o Sistema de Análise de Variância para Dados Balanceados (FERREIRA, 2000), sendo a comparação de médias feita pelo teste Tukey, a de $5 \%$ significância, para os níveis dos fatores qualitativos (épocas de coleta das estacas, veículos de diluição do AIB e substratos). O mesmo recurso computacional foi utilizado para ajustar modelos de regressão para diferentes concentrações do AIB.

\section{RESULTADOS E DISCUSSÃO}

Não foram constatadas diferenças entre a solução hidroalcoólica e $\mathrm{NaOH}$, veículos utilizados na diluição do
AIB (Tabela 1). No entanto, observaram-se diferenças significativas para os tipos de substratos utilizados e a interação entre épocas de coleta das estacas e concentrações de AIB.

Quando em baixa concentração, as substâncias químicas utilizadas para a diluição do regulador de crescimento, não permite a total diluição do AIB. Em alta concentração, por sua vez, dependendo da espécie trabalhada, pode necrosar o tecido da base das estacas, prejudicando o processo de enraizamento. A não observação de diferença significativa nos valores das variáveis consideradas na presente pesquisa indica que não houve danos às células da base das estacas responsáveis pelos primórdios de raízes, podendo ser utilizado os dois diluentes. Caballero (1981) sugere a diluição do AIB em solução hidroalcoólica 1:1, ao considerar a facilidade para sua preparação.

Entre os substratos utilizados, constatou-se que a perlita agrícola mais vermiculita promoveu incremento de $0,32 \mathrm{~cm}$ no comprimento médio das raízes, em relação às estacas em perlita agrícola (Tabela 2). Os demais parâmetros avaliados não diferiram. Possivelmente, a estrutura física das partículas da perlita agrícola não foram melhoradas com a mistura de vermiculita, a ponto de promover ganhos significativos na rizogênese das estacas de oliveira.

O substrato pode alterar a arquitetura do sistema radicular, sendo de grande importância a sua aeração e aderência às raízes (PASQUAL et al., 2001). Em decorrência da sua grande influência na produção de mudas, deve-se dar especial atenção à escolha do substrato, podendo apresentar vantagens e desvantagens, em função, principalmente, da espécie frutífera com que se está trabalhando. É necessário verificar, para cada espécie, qual o melhor substrato ou a melhor combinação (mistura) de substrato a ser utilizada (FACHINELLO et al., 1995b).

Coletadas em junho, as estacas apresentaram-se em maior porcentagem com calos (Tabela 3). Na interação entre as concentrações de AIB (Figura 1), nota-se que estacas não tratadas com AIB e coletadas nesse período tiveram $16,1 \%$ de formação de calos, contra 12,8 \% das estacas coletadas em agosto, 9,4\% em abril e apenas 0,7\% e $0,9 \%$ em julho e maio. Também é possível observa-se pela Figura 1, uma diminuição da porcentagem de estacas com calo em concentrações de AIB próximas a $1000 \mathrm{mg} . \mathrm{L}^{-1}$, especialmente em junho, tendendo a se estabilizar em seguida. 
Tabela 1 - Porcentagem de estacas com calo e enraizadas, número e comprimento médio das raízes de estacas de oliveira, tratadas com AIB diluído em diferentes veículos. Epamig, Maria da Fé-MG, 2006.

\begin{tabular}{lcccc}
\hline $\begin{array}{c}\text { Veículo de diluição } \\
\text { do AIB }\end{array}$ & $\begin{array}{c}\text { Estacas com } \\
\text { calo }(\%)\end{array}$ & $\begin{array}{c}\text { Enraizamento } \\
(\%)\end{array}$ & $\begin{array}{c}\text { Número de } \\
\text { raízes }\end{array}$ & $\begin{array}{c}\text { Comprimento médio } \\
\text { das raízes }(\mathrm{cm})\end{array}$ \\
\hline $\mathrm{NaOH} 0,5 \mathrm{~N}$ & $5,25^{\mathrm{ns}}$ & $10,23^{\mathrm{ns}}$ & $1,33^{\mathrm{ns}}$ & $0,60^{\mathrm{ns}}$ \\
Álcool + Água $(1: 1)$ & 5,26 & 9,05 & 1,68 & 0,46 \\
\hline C.V. $(\%)$ & 34,24 & 35,57 & 37,41 & 39,69 \\
\hline
\end{tabular}

ns - não significativo a $5 \%$.

Tabela 2 - Porcentagem de estacas com calo e enraizadas, número médio e comprimento médio das raízes de estacas de oliveira em dois substratos. Epamig, Maria da Fé-MG, 2006.

\begin{tabular}{lcccc}
\hline \multicolumn{1}{c}{ Substratos } & $\begin{array}{c}\text { Estacas com calo } \\
(\%)\end{array}$ & $\begin{array}{c}\text { Enraizamento } \\
(\%)\end{array}$ & $\begin{array}{c}\text { Número de } \\
\text { raízes }\end{array}$ & $\begin{array}{c}\text { Comprimento médio } \\
\text { das raízes }(\mathrm{cm})\end{array}$ \\
\hline Perlita & $5,93 \mathrm{a}$ & $9,70 \mathrm{a}$ & $1,61 \mathrm{a}$ & $0,37 \mathrm{~b}$ \\
Perlita + Vermiculita $(1: 1)$ & $4,49 \mathrm{a}$ & $9,58 \mathrm{a}$ & $1,40 \mathrm{a}$ & $0,69 \mathrm{a}$ \\
\hline C.V. $(\%)$ & 34,24 & 35,57 & 37,41 & 39,69 \\
\hline
\end{tabular}

Médias seguidas pela mesma letra na coluna não diferem pelo teste Tukey, a 5\% de probabilidade.

Tabela 3 - Porcentagem de estacas com calo e enraizadas, número médio e comprimento médio das raízes de estacas de oliveira coletadas em diferentes épocas. Epamig, Maria da Fé-MG, 2006.

\begin{tabular}{lcccc}
\hline \multicolumn{1}{c}{ Estaquia } & $\begin{array}{c}\text { Enraizamento } \\
(\%)\end{array}$ & $\begin{array}{c}\text { Estacas com calo } \\
(\%)\end{array}$ & $\begin{array}{c}\text { Número de } \\
\text { raízes }\end{array}$ & $\begin{array}{c}\text { Comprimento médio } \\
\text { das raízes }(\mathrm{cm})\end{array}$ \\
\hline Abril & $19,52 \mathrm{a}$ & $5,95 \mathrm{~b}$ & $2,22 \mathrm{ab}$ & $0,77 \mathrm{ab}$ \\
Maio & $3,81 \mathrm{~b}$ & $1,18 \mathrm{~b}$ & $0,46 \mathrm{c}$ & $0,09 \mathrm{c}$ \\
Junho & $14,78 \mathrm{a}$ & $11,39 \mathrm{a}$ & $1,07 \mathrm{c}$ & $1,04 \mathrm{a}$ \\
julho & $2,95 \mathrm{~b}$ & $1,98 \mathrm{~b}$ & $1,35 \mathrm{bc}$ & $0,50 \mathrm{bc}$ \\
Agosto & $7,29 \mathrm{~b}$ & $4,92 \mathrm{~b}$ & $2,45 \mathrm{a}$ & $0,26 \mathrm{c}$ \\
\hline C.V. $(\%)$ & 35,57 & 34,24 & 37,41 & 39,69 \\
\hline
\end{tabular}

Médias seguidas pela mesma letra na coluna não diferem pelo teste Tukey, a 5\% de probabilidade.

Maiores porcentagens de enraizamento foram obtidas em estacas coletadas em abril e junho. As demais épocas não diferenciaram entre si (Tabela 3). Em abril, houve resposta linear crescente de enraizamento com o aumento das concentrações de AIB, em média 7,6\%, para cada 1000 mg. $\mathrm{L}^{-1}$ de AIB acrescentado na solução de tratamento. Aplicando 3000 mg.L. $\mathrm{L}^{-1}$ de AIB pode-se alcançar um índice de $31,0 \%$ de enraizamento, em abril. Esse ganho, levandose em consideração uma produção de mudas em larga escala, é bastante significativo no aspecto técnico e rentável para o viveirista. Em junho, o enraizamento teve melhor resposta para concentrações próximas de $2000 \mathrm{mg} . \mathrm{L}^{-1} \mathrm{de}$ AIB.

Resultados de porcentagem de enraizamento semelhantes aos observados no presente trabalho, em torno de $30 \%$, também foram observados por Caballero (1981) e Oliveira (2001), tendo esse último trabalhado com a mesma cultivar, sob condições de casa de vegetação rústica.

O preparo de estacas semilenhosas para enraizamento, a partir de ramos colhidos de plantas adultas ou em produção, está condicionado ao estágio fenológico em que se encontra a planta (CABALLERO, 1979). Esse fato provavelmente explica os melhores resultados de enraizamento obtidos no presente trabalho, que foram observados nas estacas coletadas no mês de abril, ou seja, aproximadamente 130 dias após a colheita da cultura, tempo esse que permitiu a recuperação das plantas, quanto a seu vigor vegetativo. 
O comprimento médio das raízes foi maior nas estacas coletadas em abril e junho (Tabela 3). Em abril, estacas tratadas com AIB, em concentração que variaram entre 1000 a $3000 \mathrm{mg} . \mathrm{L}^{-1}$, proporcionaram aumento no comprimento médio das raízes de $0,8 \mathrm{~cm}$ para 1,6 cm (Figura 3). Em junho, o aumento no comprimento médio das raízes foi ainda mais expressivo, variando de $0,7 \mathrm{~cm}$ a $1,9 \mathrm{~cm}$, considerando-se as mesmas concentrações de AIB.

O número médio de raízes foi maior nas estacas coletadas em agosto e abril (Tabela 3), sendo que as concentrações entre 2000 a $3000 \mathrm{mg} . \mathrm{L}^{-1}$ de AIB promoveram melhores resultados (Figura 4).

No período de 65 dias houve queda de folhas, restando, das 4 mantidas por estaca, apenas 1 folha, em média. Essa perda de folhas, possivelmente, levou a uma intensa morte de estacas, em torno de $60 \%$, que seria certamente de $100 \%$ não fosse o efeito de proteção possibilitado pela câmara úmida. Esse resultado reforça a importância da nebulização intermitente para manutenção da permanência das folhas.

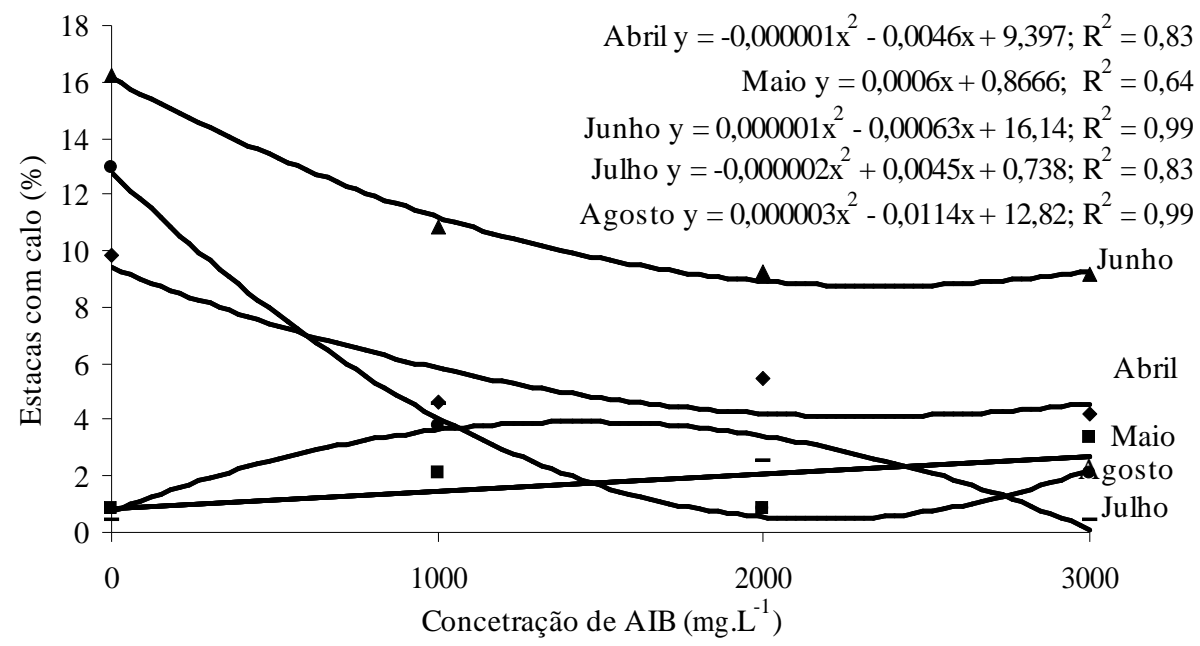

Figura 1 - Influência de concentrações de AIB na porcentagem de estacas de oliveira com calo, coletadas em diferentes épocas. Epamig, Maria da Fé-MG, 2006.

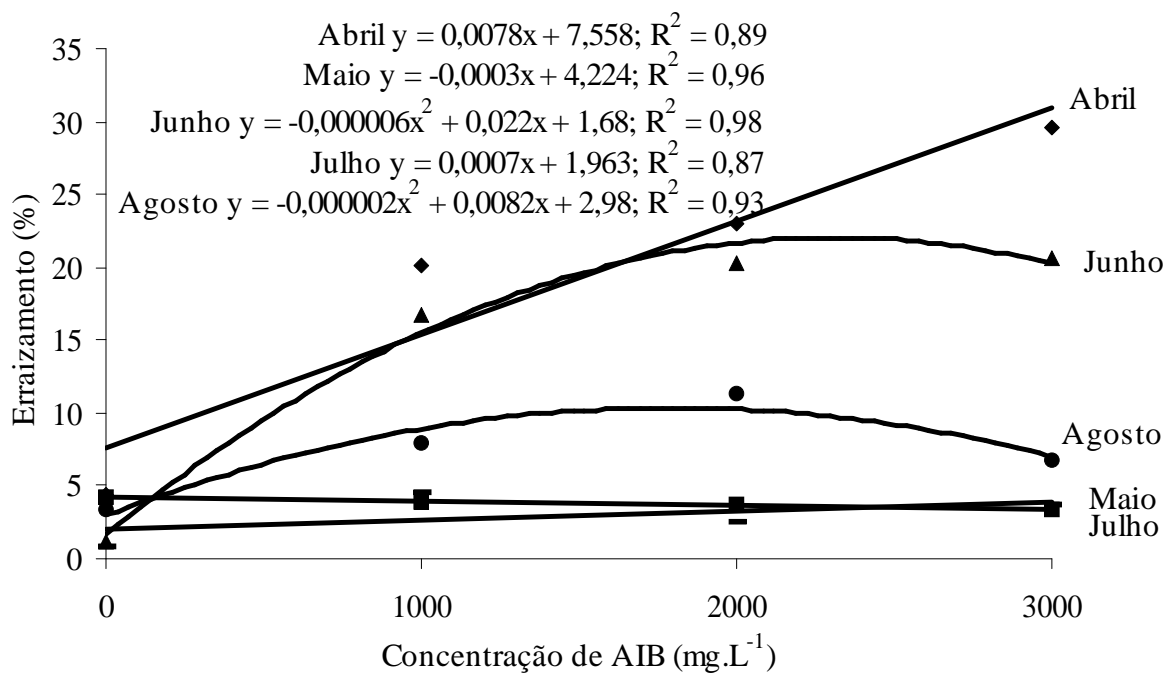

Figura 2 - Influência de concentrações de AIB na porcentagem de estacas enraizadas de oliveira coletadas em diferentes épocas. Epamig, Maria da Fé-MG, 2006. 


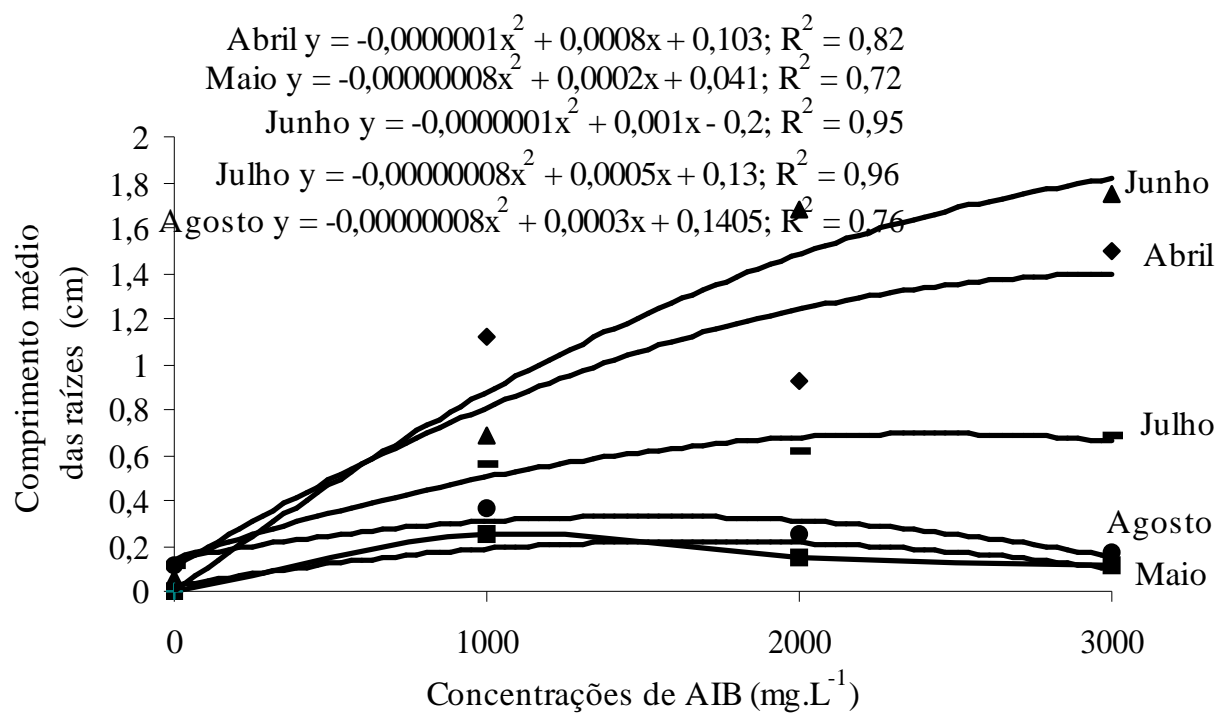

Figura 3 - Influência de concentrações de AIB no comprimento médio de raízes em estacas de oliveira coletadas em diferentes épocas. Epamig, Maria da Fé-MG, 2006.

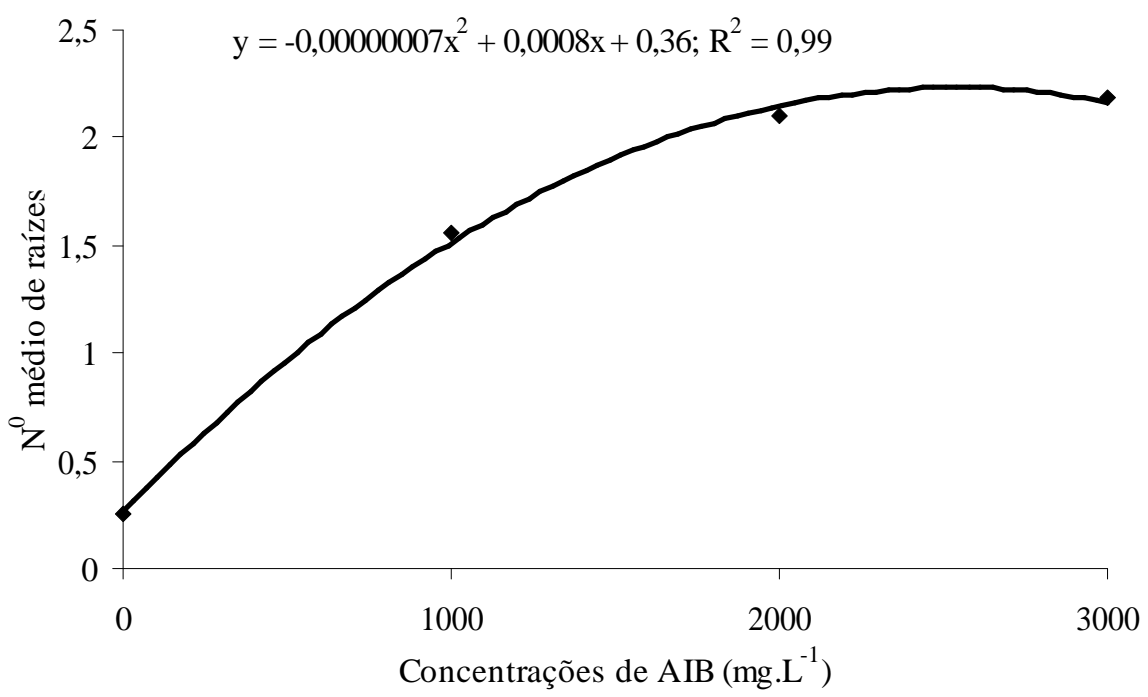

Figura 4 - Influência de concentrações de AIB no número médio de raízes por estaca de oliveira. Epamig, Maria da Fé-MG, 2006.

Oliveira (2001), utilizando estacas semilenhosas de oliveira com duas folhas, em câmara de nebulização intermitente, também observou baixo porcentual de enraizamento $12,5 \%$ e alta mortalidade de estacas 62 $\%$. Os resultados observados em ambos os experimentos demonstram a importância da manutenção de folhas nas estacas para a ocorrência de um bom enraizamento.
Mesmo considerando-se a alta porcentagem de estacas mortas, o sistema de propagação apresentado pode ainda ser considerado vantajoso. Uma câmara, nas dimensões utilizadas no presente trabalho, possibilitaria colocar para enraizamento, aproximadamente, 2500 estacas. Considerando uma média de enraizamento de $30 \%$, seria possível obter 750 estacas enraizadas ou 600 mudas, considerando uma perda de $20 \%$ em viveiro. Essa quantidade de mudas seria suficiente para o plantio de 1,2 ha, no espaçamento de 4 x $5 \mathrm{~m}$. 


\section{CONCLUSÕES}

A maior porcentagem de enraizamento e número de raízes por estaca é obtida com a estaquia de oliveira 'Ascolano 315' em abril, tratadas com 3000 mg.L $\mathrm{L}^{-1}$ de AIB.

O substrato perlita + vermiculita $(1: 1 \mathrm{v} / \mathrm{v})$ incrementou apenas o comprimento médio das raízes.

A diluição do AIB em $\mathrm{NaOH}$ ou álcool não difere quanto à indução do enraizamento, sendo recomendado o álcool pela facilidade de sua obtenção.

\section{REFERÊNCIAS BIBLIOGRÁFICAS}

CABALLERO, J. M. Multiplicación del olivo por estaquillado semileñoso bajo nebulización. Madrid: Comunicaciónes I.N.I.A., 1981. 39 p. (Série producción vegetal, 31).

CABALLERO, J. M. Endogenous rooting promoters and inhibitors for olive cultivars (Olea europaea L.): promotores e inhibidores endogenos de la iniciacion radical en olivo (Olea europaea L.). Anales Del Instituto Nacional de Investigaciones Agrárias, Madrid, v. 11, p. 201-217, 1979.

CASTRO, C.; GUERREIRO, M.; CALDEIRA, F.; PINTO, P. Aspectos generales del sector oleícola em Portugal. Fruticultura Profesional, Barcelona, n. 88, p. 28-35, 1997. Especial olivicultura, 2.

FACHINELLO, J. C.; HOFFMANN, A.; NACHTIGAL, J. C. Propagação de plantas frutíferas. Brasília, DF: Embrapa Informação Tecnológica, 2005a. 221 p.

FACHINELLO, J. C.; HOFFMANN, A.; NACHTIGAL, J. C.; KERSTEN, E.; FORTES, G. R. de L. Propagação de plantas frutíferas de clima temperado. 2. ed. Pelotas: UFPel, 1995b. 178 p.

FERREIRA, D. F. Análise estatística por meio do SISVAR (Sistema para Análise de Variância) para Windows versão 4.0. In: REUNIÃO ANUAL DA REGIÃO BRASILEIRA DA SOCIEDADE INTERNACIONAL DE BIOMETRIA, 45., 2000, São Carlos. Anais... São Carlos: UFSCar, 2000. p. 255258.
HARTMANN, H. T.; KESTER, D. E.; DAVIES JUNIOR, F. T.; GENEVE, R. L. Plant propagation: principles and practices. 7. ed. New Jersey: Prentice Hall, 2002. 880 p.

JACOBONI, N.; BATTAGLINI, M.; PERZIOSI, P. Propagación del olivo. In: Olivicultura moderna. Madrid: FAO-INIA, 1976. cap. 6, p. 150-169.

MESQUITA, D. L.; OLIVEIRA, A. F. de; MESQUITA, H. A. de. Aspectos econômicos da produção e comercialização do azeite de oliva e azeitona. Informe Agropecuário, Belo Horizonte, v. 27, n. 231, p. 7-12, 2006.

OLIVEIRA, A. F. de. Estudo de diferentes métodos de multiplicação de oliveira (Olea europaea L.) e influência no desenvolvimento vegetativo. In: CONGRESSO BRASILEIRO DE FRUTICULTURA, 1998, Poços de Caldas. Anais... Poços de Caldas: SBF, 1998. p. 633.

OLIVEIRA, A. F. de. Enraizamento de estacas semilenhosas e cultura de embriões in vitro de oliveira (Olea europaea L.). 2001. 122 f. Tese (Doutorado em Fitotecnia) - Universidade Federal de Lavras, Lavras, 2001.

OLIVEIRA, A. F. de; ABRAHÃO, E. Botânica e morfologia da oliveira (Olea europaea L.). Informe Agropecuário, Belo Horizonte, v. 27, n. 231, p. 13-17, 2006.

PASQUAL, M.; CHALFUN, N. N. J.; RAMOS, J. D.; VALE, M. R. do; SILVA, C. R. de R. Fruticultura comercial: propagação de plantas frutíferas. Lavras: UFLA/FAEPE, 2001.137 p.

PIEDRA, A. P.; MARTIN, S.; CAMACHO, F. P.; FERNÁNDEZ, E. C. Nueva tecnología para sistemas de control de propagación de plantas bajo nebulización. Olivae, Madrid, n. 41, p. 16-23, 1992.

PORRAS, A.; MARTIN, M. L. S.; MALDONADO, P. S. Mejora técnicas de la propagación del olivo bajo nebulización. Olivae, Madrid, n. 74, p. 58-61, 1998. 